\title{
Producción científica y características de docentes universitarios de Educación
} Física del Perú

\section{Scientific production and characteristics of university teachers of Physical Education in Peru}

Alcides Flores Paredes ${ }^{\mathbf{1}}$; Yony Martín Pino Vanegas ${ }^{\mathbf{1}}$; Daniel Coila Pancca ${ }^{\mathbf{1} 2}$; Sergio Néstor Condori Huanca ${ }^{\mathbf{1} 2}$; Jhonatan Thonny Macedo Atamari ${ }^{\mathbf{1 2}}$; Agustín Moisés Ticona Quiza $^{3}$; Leoncio Eleodoro Zeballos Zapana ${ }^{4}$

${ }^{1}$ Universidad Nacional del Altiplano, Facultad de Ciencias de la Educación, Escuela Profesional de Educación Física, Puno, Perú.

1,2Maestría en Ciencias del Deporte

3Instituto de Educación Superior Pedagógico Público de Educación Física-Lampa ${ }^{4}$ Instituto de Educación Superior Pedagógico Público de Juliaca

Contacto: alcidesflores@unap.edu.pe

Cronograma editorial: Artículo recibido: 14/06/2020 Aceptado: 08/07/2020 Publicado: 01/09/2020 DOI: https://doi.org/10.17979/sportis.2020.6.3.6600

Para citar este artículo utilice la siguiente referencia: Flores Paredes, A.; Martín Pino Vanegas, Y.; Coila Pancca, D.; Condori Huanca, S.N.; Macedo Atamari, J.T. ; Ticona Quizá, A.M.; Zeballos Zapana, L. (2020). Producción científica y características de docentes universitarios de Educación Física del Perú. Sportis Sci J, 6 (3), 447-467.

DOI: https://doi.org/10.17979/sportis.2020.6.3.6600

http://revistas.udc.es/ 


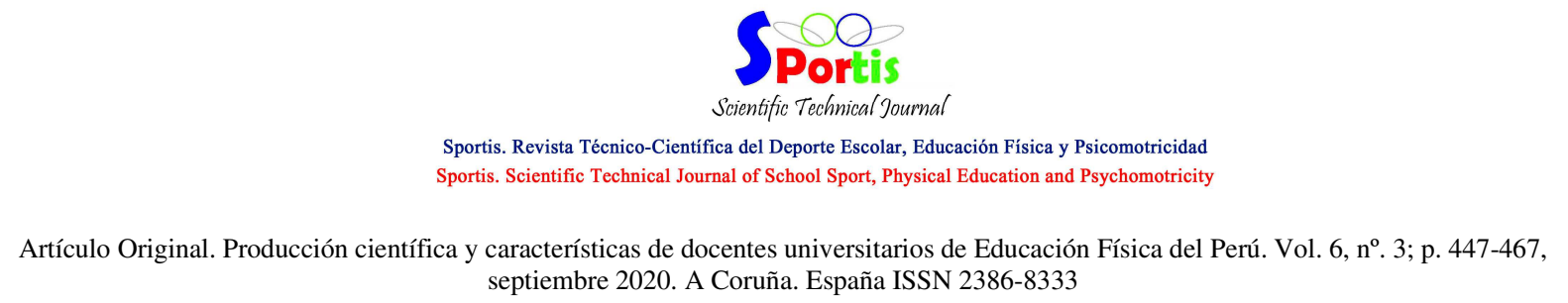

\title{
Resumen
}

Frente a la problemática producción científica en la docencia universitaria en el Perú, y el insuficiente aporte de publicaciones por parte de los docentes, se tuvo como objetivo determinar la frecuencia de publicación científica de doctores, magísteres y licenciados e identificar los factores asociados. Para esto se realizó un estudió observacional, descriptivo y transversal en una población conformada por 165 docentes (135 varones con $57.49 \pm 3.73$ y 30 mujeres $55.75 \pm 0.80$ ), la investigación utilizó el método científico, el enfoque de investigación cuantitativo, la búsqueda de artículos se realizó en la base de datos de Google Académico y Scopus publicados en el periodo del (2006 a mayo del 2020), que consignaron al menos un autor con la filiación y base de datos indexada. El 45.19\% (61) tienen el grado de maestría, $34.07 \%$ (46) grado de doctor, y un $20.74 \%$ (28) con título profesional, en comparación con el sexo femenino $36.67 \%$ (11) con grado de maestría, 33.33\% (10) con título profesional, y un $30 \%$ (9) con el grado de doctor. El mayor porcentaje de investigaciones lo realizaron (5) doctores con 25 publicaciones en Scopus, 10 en Web of sience, 9 en Pub med, 2 en Scielo y 2 en Latindex. En comparación a los magísteres, 1 en Web of Science y en Latindex, y 3 docentes cuentan con la certificación de docente investigador reconocidos por el (RENACYT). Se concluye que son muy bajas las frecuencias de publicaciones de los docentes universitarios de Educación Física con título profesional, maestrías y doctorados.

\section{Palabras Clave}

Docentes; Educación Física; producción científica

\begin{abstract}
Faced with the problematic scientific production in university teaching in Peru, and the insufficient contribution of publications by teachers, the objective was to determine the frequency of scientific publication of doctors, masters and graduates and to identify the associated factors. For this, an observational, descriptive and cross-sectional study was carried out in a population made up of 165 teachers (135 men with $57.49 \pm 3.73$ and 30 women 55.75 \pm 0.80 ), the research used the scientific method, the quantitative research approach, the search for articles It was performed in the Google Academic and Scopus database published in the period from (2006 to May 2020), which recorded at least one author with the affiliation and indexed database. $45.19 \%$ (61) have a master's degree, $34.07 \%$ (46) a doctor's degree, and $20.74 \%$ (28) have a professional degree, compared to the female gender $36.67 \%$ (11) have a master's degree, $33.33 \%$ (10) with a professional title, and 30\% (9) with a doctor's degree. The highest percentage of research was carried out by (5) doctors with 25 publications in Scopus, 10 in Web of sience, 9 in Pub med, 2 in Scielo and 2 in Latindex. In comparison to the master's degrees, 1 in Web of Science and in Latindex, and 3 teachers have the certification of research professor recognized by the (RENACYT). It is concluded that the frequencies of publications of the physical education university professors with a professional title, masters and doctorates are very low.
\end{abstract}

Para citar este artículo utilice la siguiente referencia: Flores Paredes, A.; Martín Pino Vanegas, Y.; Coila Pancca, D.; Condori Huanca, S.N.; Macedo Atamari, J.T. ; Ticona Quizá, A.M.; Zeballos Zapana, L. (2020). Producción científica y características de docentes universitarios de Educación Física del Perú. Sportis Sci J, 6 (3), 447-467.

DOI: https://doi.org/10.17979/sportis.2020.6.3.6600

http://revistas.udc.es/ 


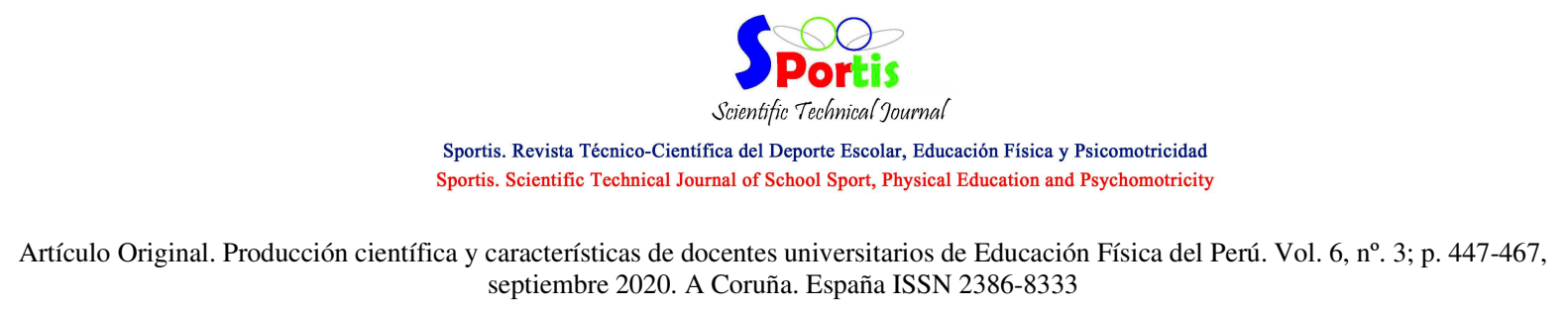

\section{Keywords}

Teachers; physical education; scientific production

\section{Introducción}

La producción científica es de medular importancia en las universidades y esta va relacionada con los países de mayor desarrollo económico. El Scimago Journal \& Country Rank (SJR) es un portal que incluye indicadores de revistas científicas que pueden ser utilizados para evaluar y analizar la producción científica y los países con mayor producción de conocimientos son: Estados Unidos lidera la lista con (12.070.144) documentos publicados, seguido por China (5.901.404), Reino Unido (3.449.243), Alemania (3.019.959), Japón (2.750.108) y España se ubica en la décima posición con (1.376.358). En América Latina, el país con mayor producción científica es Brasil (décimo quinto lugar a nivel mundial) con (938.352) documentos publicados, seguido de México (318.095), Argentina (209.294), Chile (147.389), Colombia (99.301) y Perú, que se ubica en el octavo lugar en la región y el septuagésimo tercer lugar a nivel mundial con (25.175) documentos (Scimago, 2020).

En el trascurso del tiempo, se ha podido apreciar en el mundo una diferenciación cada vez mayor en las formas y las capacidades institucionales de las universidades. En Latinoamérica, de manera particular en México, ha iniciado tardíamente la transformación de sus universidades hacia el desarrollo de capacidades de investigación y de transferencia de conocimiento (Arechavala y Sánchez, 2017). La publicación científica es la herramienta que utilizan los investigadores para transmitir información. Se trata del proceso de legitimación de los resultados obtenidos. La rápida irrupción de revistas científicas electrónicas enfrenta al profesional a una fuente inagotable de información (Pascual y Martínez, 2010).

La Universidad debe asumir su función elemental como productora del intelecto y responder con productividad, eficiencia y eficacia ante estos retos contemporáneos; para lograr este propósito se requiere de una serie de condiciones que garanticen el desarrollo de la investigación en la misma, mediante estrategias orientadas a la promoción de actitudes que favorezcan la actividad investigadora y que involucren a docentes, estudiantes, egresados,

Para citar este artículo utilice la siguiente referencia: Flores Paredes, A.; Martín Pino Vanegas, Y.; Coila Pancca, D.; Condori Huanca, S.N.; Macedo Atamari, J.T. ; Ticona Quizá, A.M.; Zeballos Zapana, L. (2020). Producción científica y características de docentes universitarios de Educación Física del Perú. Sportis Sci J, 6 (3), 447-467. 


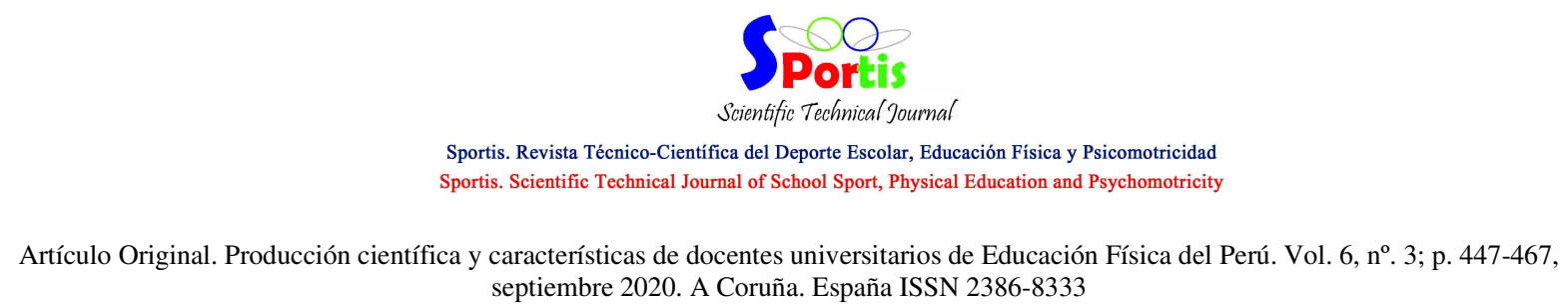

grupos de interés engarzados con la problemática y necesidades de la sociedad (Barbón y Bascó, 2016). Y así mismo fortalecer la edición de revistas científicas que vienen asumiendo las universidades en Latinoamérica, asociado a su función misional de investigación (Rodríguez, González y Maqueda, 2017).

La investigación científica se sitúa en el propio corazón de la ciencia. Un experimento científico, por espectaculares que sean sus resultados, no termina hasta que esos resultados se publican, pues solo así pueden verificarse los nuevos conocimientos. Y la forma más común y reconocida mundialmente para llevar a cabo esta comunicación ha sido la publicación, en revistas científicas, en monografías o en patentes y normas (Rodríguez, González y González 2016). De igual modo, la divulgación de la ciencia, en forma de artículos científicos, ha dejado de ser una opción y se ha transformado en una necesidad para los docentes universitarios (Barbón, et al., 2019).

Asimismo, existen limitaciones donde no se cuenta con un plan sostenible de incentivos. Carranza y Turpo (2019) señalan que la inversión en investigación según la UNESCO es del 4,7\% para Israel, del 2,7\% para los Estados Unidos, del 1,1\% para Brasil y del 0,1\% para Perú. Esto, en la era de la gestión del conocimiento, hace que esté relegado el tema presupuestal de investigación. El poco presupuesto es dado a pagar planillas de investigadores, como tratar de habilitar laboratorios, pero no existe el plan sostenible de incentivos, y si lo hay, su ejecución depende de gestiones burocráticas.

Por otro lado, se necesita la conformación de modelos universitarios que vinculen la investigación con la formación profesional y académica ya que constituye un proceso vital para esas instituciones y los aportes a que estas están comprometidas en su contexto social (Gutiérrez, Peralta y Fuentes, 2019). Además, existe una relación lineal positiva entre los años de acreditación institucional y el número de miembros de la Facultad que poseen un doctorado, trabajos de investigación publicados y proyectos, y esto debe favorecer los procesos de acreditación de las instituciones de Educación Superior (Barra, 2019; Rodríguez, et al., 2016).

En Perú, en el 2014 se aprobó la Ley N³0220, Ley Universitaria en su artículo 48. Señala que la investigación constituye una función esencial y obligatoria de la Universidad,

Para citar este artículo utilice la siguiente referencia: Flores Paredes, A.; Martín Pino Vanegas, Y.; Coila Pancca, D.; Condori Huanca, S.N.; Macedo Atamari, J.T. ; Ticona Quizá, A.M.; Zeballos Zapana, L. (2020). Producción científica y características de docentes universitarios de Educación Física del Perú. Sportis Sci J, 6 (3), 447-467.

DOI: https://doi.org/10.17979/sportis.2020.6.3.6600

http://revistas.udc.es/ 


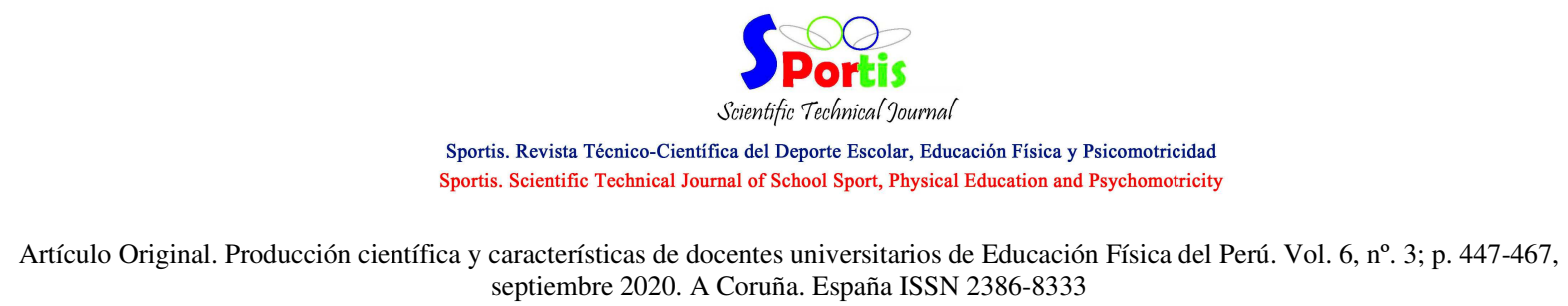

que la fomenta y realiza, respondiendo a través de la producción de conocimiento y desarrollo de tecnologías a las necesidades de la sociedad, con especial énfasis en la realidad nacional (Ley Universitaria $\left.\mathrm{N}^{\circ} 30220,2014\right)$. En el marco de la ley, se creó la Superintendencia Nacional de Educación Superior Universitaria, 2016 (SUNEDU), encargada del licenciamiento y supervisión del servicio educativo superior universitario, y de la fiscalización del uso de los recursos públicos y beneficios que son otorgados a las universidades para fines educativos y de mejoramiento de la calidad.

En el Perú no se ha investigado este grupo en concreto, pero se tienen algunos estudios en poblaciones similares en donde, desarrollar la producción científica en las universidades del Perú y de Latinoamérica es una prioridad y una necesidad. Encontramos que la participación del Perú en la publicación de trabajos científicos en Latinoamérica es del 1,1\%, y a nivel mundial representa solo el 0,05\% (CONCYTEC, 2014); este reducido porcentaje de participación incluye el área de medicina, que constituye una de las de mayor producción a nivel internacional. De manera que, la publicación de artículos en revistas científicas indexadas es un componente de la evaluación de la actividad investigadora de los profesores universitarios. Frente a este desafío, adquiere un rol protagónico la competencia en la elaboración de artículos científicos, principal forma de comunicar la ciencia entre las comunidades científicas (Luque, 2015).

Los investigadores están sujetos a múltiples instancias en las que se evalúa su producción académica. Basados en indicadores bibliométricos y en información sobre indexaciones, por consiguiente, permiten detectar las principales revistas, organizaciones y autores que han trabajado en el tema. A partir de un estudio de conjunto de palabras se evidencian las principales líneas de investigación, destacándose entre ellas la medición de la productividad de la investigación (King, Llinás y Améstica, 2020; Vasen y Lujano, 2017). Por otra parte, entre los docentes no existe tal grado de acuerdo, quedando de manifiesto la posición argumental de que la categoría y el prestigio académico e investigador del profesor son indicadores reales de una mayor calidad en la docencia (Hortigüela, Ausín, Delgado y Abella, 2017).

Para citar este artículo utilice la siguiente referencia: Flores Paredes, A.; Martín Pino Vanegas, Y.; Coila Pancca, D.; Condori Huanca, S.N.; Macedo Atamari, J.T. ; Ticona Quizá, A.M.; Zeballos Zapana, L. (2020). Producción científica y características de docentes universitarios de Educación Física del Perú. Sportis Sci J, 6 (3), 447-467.

DOI: https://doi.org/10.17979/sportis.2020.6.3.6600

http://revistas.udc.es/ 


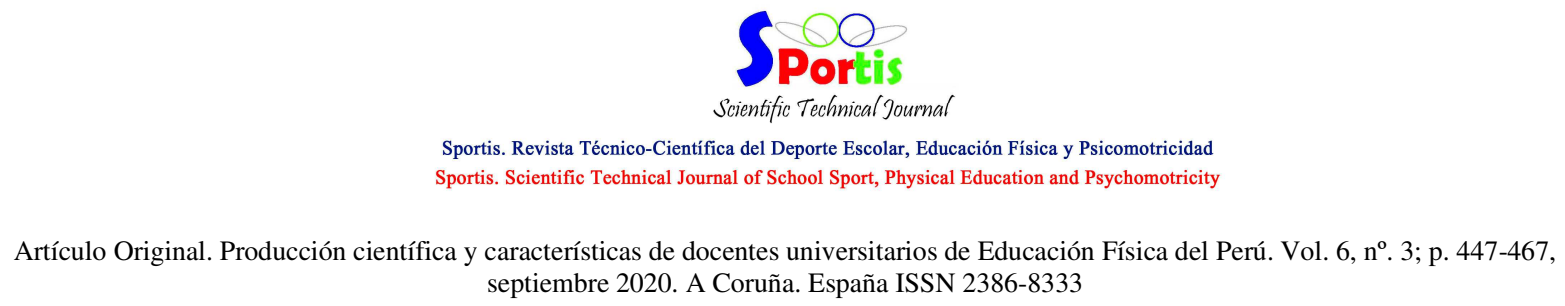

Los docentes universitarios desempeñan un papel importante como influencia para que los alumnos de pregrado realicen investigación, pero esta influencia no será adecuada si estos no han realizado con anterioridad investigación. Los estudiantes se sienten más motivados para trabajar en líneas de investigación si esta es liderada por un docente y más de la mitad de los estudiantes investigadores refieren que la principal motivación para empezar en el mundo de la investigación son los docentes modelos y con repercusión en las distintas áreas de investigación (Chachaima, Fernández y Atamari, 2019; Linn, Palmer, Baranger, Gerard, \& Stone, 2015).

Se necesita transitar hacia la organización de los grupos de investigación en determinadas áreas con identidad académica, conformado por equipos de trabajo que incorporan a profesionales de diferentes especialidades, médicos, bioquímicos, enfermeras residentes de investigación, así como también a otros profesionales de la salud. Lo anterior ha sido incorporado en algunos equipos a nivel nacional y es en ellos donde se ha evidenciado una mayor cantidad de postulación a proyectos de investigación, así como difusión de conocimientos en congresos y aumento del número de publicaciones (López y Zárate, 2019; Sime, 2017).

El desafío sigue siendo hacer que todo este diálogo de producción, investigación, práctica pedagógica en educación física, entrenamiento deportivo y ocio, poniéndolo al servicio de la intervención en la cancha, en la escuela, en el club, en la plaza, en el gimnasio, entre muchos otros espacios en los que el cuerpo y las prácticas corporales juegan un papel principal (Fernandez, Quintão y Bassani, 2017). De manera similar es necesario fomentar la crítica (científica) que permita mejorar la escritura de los textos científicos y una comunicación eficaz entre autores y lectores. Con ello se cumple el cometido de que todo artículo requiere ser publicado y comprendido, aparte de acrecentar el conocimiento científico y resolver problemas (en caso de la investigación aplicada) (González y Rubio, 2019).

Finalmente, la Universidad tiene una misión formativa y otra investigadora; en este sentido, las reflexiones vertidas tienen como finalidad mostrar las limitaciones de producción científica en Perú en el contexto estudiantil y docente, pues se considera que la producción científica es muy importante porque a través de los hallazgos se enriquece la ciencia (Barbón

Para citar este artículo utilice la siguiente referencia: Flores Paredes, A.; Martín Pino Vanegas, Y.; Coila Pancca, D.; Condori Huanca, S.N.; Macedo Atamari, J.T. ; Ticona Quizá, A.M.; Zeballos Zapana, L. (2020). Producción científica y características de docentes universitarios de Educación Física del Perú. Sportis Sci J, 6 (3), 447-467.

DOI: https://doi.org/10.17979/sportis.2020.6.3.6600

http://revistas.udc.es/ 


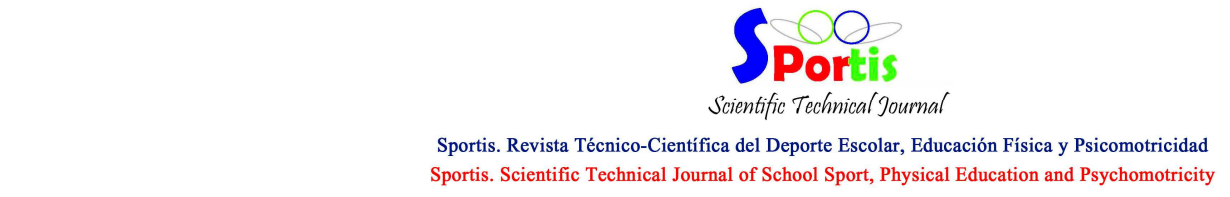

Artículo Original. Producción científica y características de docentes universitarios de Educación Física del Perú. Vol. 6, nº 3; p. 447-467, septiembre 2020. A Coruña. España ISSN 2386-8333

y Bascó, 2016). El objetivo de nuestro estudio fue determinar la frecuencia de publicación científica en doctores, magísteres y licenciados peruanos, así como identificar los factores asociados según el tipo de base (Google Académico y Scopus) y periodo de publicación.

\section{Material y Método}

\section{Diseño de investigación}

La investigación asumió el diseño observacional, descriptivo y transversal, que tienen como objetivo indagar la incidencia de las modalidades o niveles de una o más variables en una población (Hernández, Fernández y Baptista, 2006).

\section{Población}

La población de la investigación estuvo conformada por las universidades peruanas que ofertan el programa de estudios de Educación Física al año académico 2019. En la cual, solo se consideraron para el estudio, docentes con la especialidad de Educación Física, suprimiéndose a docentes de otras áreas.

Tabla 1. Descripción de la población

\begin{tabular}{llccc}
\hline $\mathrm{N}^{\circ}$ & $\begin{array}{c}\text { Universidades que ofertan el programa de } \\
\text { estudios de Educación Física }\end{array}$ & Varones & Mujeres & Total \\
\hline 01 & Universidad Nacional Mayor de San Marcos & 25 & 5 & 30 \\
& $\begin{array}{l}\text { Universidad Nacional de Educación Enrique } \\
\text { Guzmán y Valle }\end{array}$ & 23 & 11 & 34 \\
& $\begin{array}{l}\text { Universidad Nacional San Luís Gonzada de } \\
03\end{array}$ & 5 & - & 5 \\
04 & Una & 16 & 4 & 20 \\
05 & Universidad Nacional del Altiplano- UNA & 17 & 2 & 19 \\
06 & Universidad Nacional Federico Villareal & 6 & - & 6 \\
07 & Universidad Nacional San Cristóbal de & 7 & - & 7 \\
08 & Unamanga & 6 & 2 & 8 \\
09 & Universidad Nacional del Callao & 4 & - & 4 \\
10 & Universidad Nacional del Centro Nacional Pedro Ruiz Gallo & 3 & - & 3 \\
Universidad Nacional de San Antonio Abad & 1 & - & 1
\end{tabular}

Para citar este artículo utilice la siguiente referencia: Flores Paredes, A.; Martín Pino Vanegas, Y.; Coila Pancca, D.; Condori Huanca, S.N.; Macedo Atamari, J.T. ; Ticona Quizá, A.M.; Zeballos Zapana, L. (2020). Producción científica y características de docentes universitarios de Educación Física del Perú. Sportis Sci J, 6 (3), 447-467.

DOI: https://doi.org/10.17979/sportis.2020.6.3.6600

http://revistas.udc.es/ 


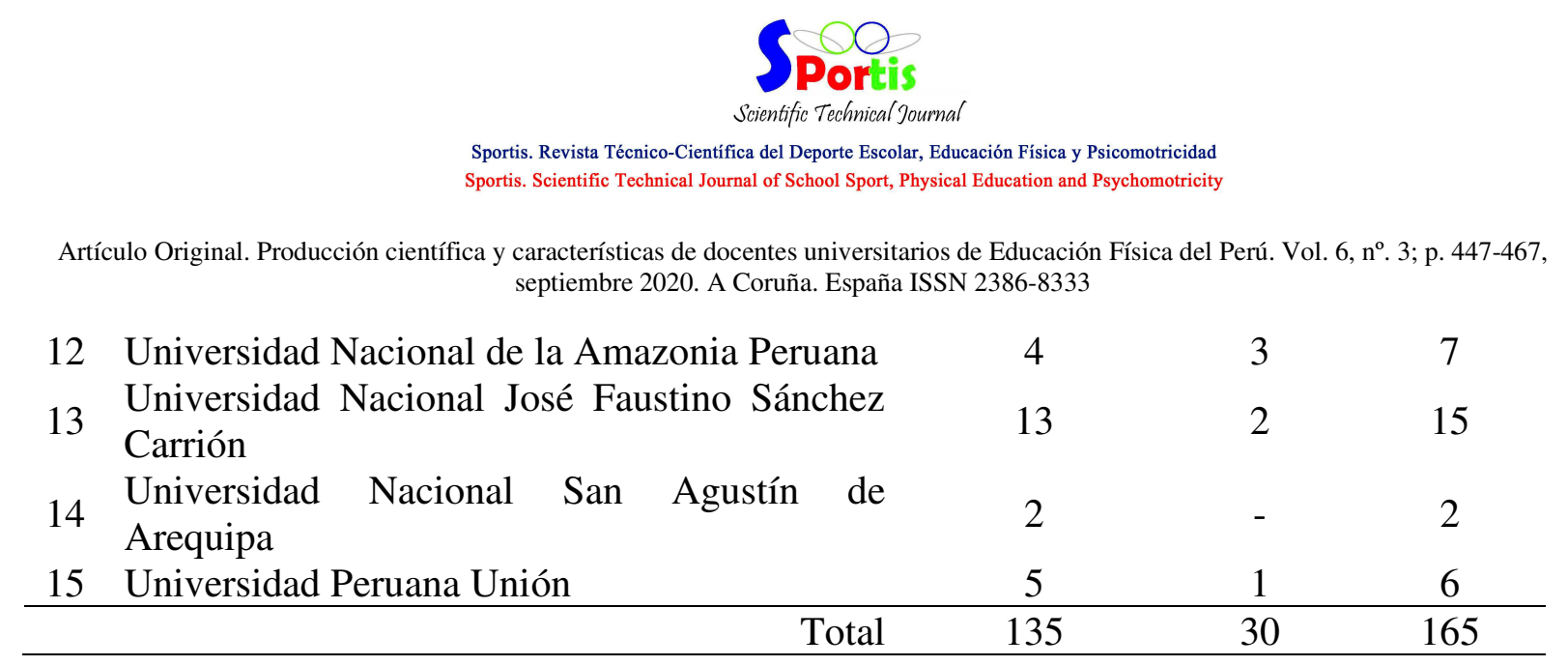

\section{Criterios de selección}

La muestra es de tipo no probabilística trabajando con el total de la población, 165 docentes universitarios (135 varones y 30 mujeres).

\section{Variables}

Se utilizaron las siguientes: grados académicos obtenidos, sexo, edad, investigaciones realizadas y se consideró como "publicación” todo artículo público en una revista científica. Se excluyeron los informes de tesis, resúmenes en congresos científicos y libros y se clasificó como "artículo" si presentaban las secciones de: introducción, métodos, resultados, discusión y conclusiones o sus equivalentes, además si pertenecen al RENACYT como investigadores.

\section{Instrumentos}

El instrumento utilizado fue la ficha de recolección de datos validada por un docente de investigación con experiencia en publicación científica.

\section{Procedimientos}

La identificación del grado académico y la categoría del docente investigador se realizó en el portal de la Superintendencia Nacional de Educación Superior Universitaria (SUNEDU) del Perú, luego se verificó en el registro nacional de grados y títulos, y en el Registro Nacional de Ciencia, Tecnología y de Innovación Tecnológica (RENACYT), del Consejo Nacional de Ciencia, Tecnología e Innovación (CONCYTEC). Para identificar la edad se utilizó el nombre y apellidos completos de los docentes de Educación Física mediante el sistema de consulta de acreditación del Seguro Social de Salud-EsSalud

Para citar este artículo utilice la siguiente referencia: Flores Paredes, A.; Martín Pino Vanegas, Y.; Coila Pancca, D.; Condori Huanca, S.N.; Macedo Atamari, J.T. ; Ticona Quizá, A.M.; Zeballos Zapana, L. (2020). Producción científica y características de docentes universitarios de Educación Física del Perú. Sportis Sci J, 6 (3), 447-467.

DOI: https://doi.org/10.17979/sportis.2020.6.3.6600

http://revistas.udc.es/ 


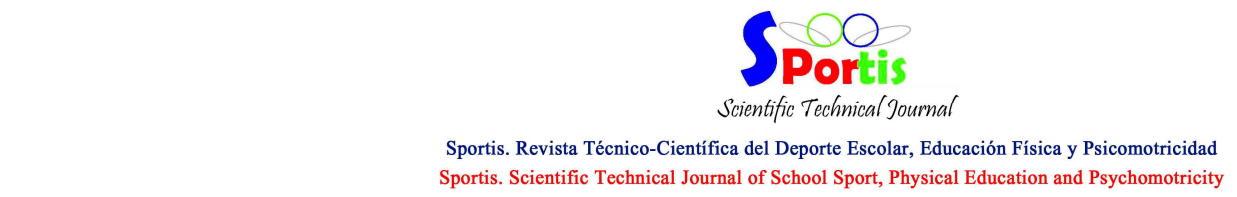

Artículo Original. Producción científica y características de docentes universitarios de Educación Física del Perú. Vol. 6, nº 3; p. 447-467, septiembre 2020. A Coruña. España ISSN 2386-8333

http://ww4.essalud.gob.pe:7777/acredita/ y para la posterior búsqueda de publicaciones. Después de obtener la edad, los datos identificatorios fueron borrados.

La indagación de publicaciones científicas se realizó en la base de datos de Scopus y en el motor de búsqueda de Google Académico, para lo cual se utilizaron combinaciones de los nombres y apellidos adicionando Perú en cada una de las bases de datos: "Apellido1Apellido2" Perú; "Nombre1 Apellido1" Perú; “Nombre inicial Nombre2 Apellido1" Perú. Se consideró la cantidad de publicaciones durante su carrera y las publicaciones de los años 2006 a mayo del 2020.

Los problemas de homonimia fueron resueltos según el país, ciudad e institución de la filiación de los autores, así como también el uso del ORCID (Open Research and Contributor ID) es un identificador único que tiene como principal finalidad proporcionar a los investigadores un código de autor persistente e inequívoco que distinga claramente su producción científica y evite confusiones vinculadas con la autoría científica y la existencia de nombres personales coincidentes o similares.

\section{Análisis estadístico}

Para el proceso estadístico se utilizó el análisis descriptivo de frecuencias y porcentajes y las medidas de tendencia central.

\section{Consideraciones bioéticas}

Respecto a los aspectos bioéticos, el presente estudio guarda la confidencialidad de los datos, además se tuvo una lista anónima para realizar el análisis estadístico.

Para citar este artículo utilice la siguiente referencia: Flores Paredes, A.; Martín Pino Vanegas, Y.; Coila Pancca, D.; Condori Huanca, S.N.; Macedo Atamari, J.T. ; Ticona Quizá, A.M.; Zeballos Zapana, L. (2020). Producción científica y características de docentes universitarios de Educación Física del Perú. Sportis Sci J, 6 (3), 447-467.

DOI: https://doi.org/10.17979/sportis.2020.6.3.6600

http://revistas.udc.es/ 
Artículo Original. Producción científica y características de docentes universitarios de Educación Física del Perú. Vol. 6, nº 3; p. 447-467, septiembre 2020. A Coruña. España ISSN 2386-8333

Tabla 2. Características de los licenciados, magísteres y doctorados de Educación Física de las Universidades del Perú.

Variables

Docentes con .... n $(\%)$

\begin{tabular}{|c|c|c|c|c|c|}
\hline \multicolumn{2}{|c|}{ Grado académico } & \multirow{2}{*}{$\begin{array}{l}\begin{array}{l}\text { Título } \\
\text { profesional }\end{array} \\
10(33.33 \%)\end{array}$} & \multirow{2}{*}{$\begin{array}{l}\text { Maestría } \\
11(36.67 \%)\end{array}$} & \multirow{2}{*}{$\begin{array}{l}\text { Doctor } \\
9(30.00 \%)\end{array}$} & \multirow{2}{*}{$\begin{array}{l}\text { Total } \\
30(100 \%)\end{array}$} \\
\hline Сонг & Femenino & & & & \\
\hline Sexo & Masculino & $28(20.74 \%)$ & $61(45.19 \%)$ & $46(34.07 \%)$ & $135(100 \%)$ \\
\hline \multirow{8}{*}{ Edad } & Femenino & $\overline{\mathrm{x}} 63.20 \pm 9.57$ & $\overline{\mathrm{X}} 49.27 \pm 7.77$ & $\bar{X} 54.78 \pm 9.34$ & $\bar{X} 55.75 \pm 0.80$ \\
\hline & Mediana & 65 & 52 & 57 & \\
\hline & $\begin{array}{l}\text { Edad } \\
\text { mínima }\end{array}$ & 39 & 34 & 42 & \\
\hline & $\begin{array}{l}\text { Edad } \\
\text { Máxima }\end{array}$ & 75 & 58 & 66 & \\
\hline & Masculino & $\bar{x} 62.75 \pm 9.87$ & $\overline{\mathrm{X}} 54.52 \pm 10.09$ & $\overline{\mathrm{X}} 55.19 \pm 10.17$ & $\overline{\mathrm{X}} 57.49 \pm 3.73$ \\
\hline & Mediana & 64 & 53 & 56 & \\
\hline & $\begin{array}{l}\text { Edad } \\
\text { mínima }\end{array}$ & 44 & 34 & 26 & \\
\hline & $\begin{array}{l}\text { Edad } \\
\text { Máxima }\end{array}$ & 77 & 74 & 78 & \\
\hline \multirow{5}{*}{ Público en: } & Scopus & No & No & Sí, 5 (100\%) & \\
\hline & $\begin{array}{l}\text { Web of } \\
\text { Science }\end{array}$ & No & Sí, 1 (9.09\%) & Sí, 10 (90.91\%) & \\
\hline & Pub Med & No & No & Sí, 9 (100\%) & \\
\hline & Scielo & No & No & Sí, 2 (100\%) & \\
\hline & Latindex & No & Sí, 1 (33.33\%) & Sí, $2(66.67 \%)$ & \\
\hline $\begin{array}{l}\text { Docentes } \\
\text { investigadores }\end{array}$ & Masculino & No & No & $\begin{array}{l}\text { Sí, (3) }(1.82 \%) \\
\text { No, } 162(98.18 \%)\end{array}$ & $165(100 \%)$ \\
\hline
\end{tabular}

De los 165 docentes de Educación Física con estudios de título, maestría y doctorado inscritos en el registro de títulos de la (SUNEDU) del Perú, el 45.19\% (61) tienen maestría, $34.07 \%$ (46) doctor, y un 20.74\% (28) título profesional, en comparación con el sexo femenino 36.67\% (11) maestría, 33.33\% (10) título profesional, y un 30\% (9) doctor. Acorde con la ley universitaria en su artículo 82 señala que para el ejercicio de la docencia universitaria es poseer el grado de Maestría para la formación en el nivel de pregrado. Del mismo modo, el promedio de edad de los docentes varones (57.49 \pm 3.73$)$, mujeres $(55.75 \pm$ Para citar este artículo utilice la siguiente referencia: Flores Paredes, A.; Martín Pino Vanegas, Y.; Coila Pancca, D.; Condori Huanca, S.N.; Macedo Atamari, J.T. ; Ticona Quizá, A.M.; Zeballos Zapana, L. (2020). Producción científica y características de docentes universitarios de Educación Física del Perú. 


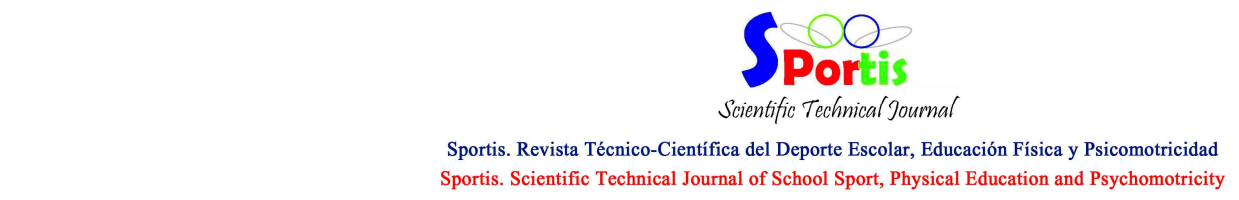

Artículo Original. Producción científica y características de docentes universitarios de Educación Física del Perú. Vol. 6, nº 3; p. 447-467, septiembre 2020. A Coruña. España ISSN 2386-8333

0.80) y el $1.82 \%$ (3) docentes con grado de doctor cuentan con certificación como investigador por parte del (RENACYT) del Perú.

Por otra parte, se muestra que la edad máxima de productividad es a los 58 años para el caso de las investigadoras y 57 años para los investigadores y las actividades de colaboración están en continuo crecimiento entre los investigadores (Rodríguez, et al., 2017).

El profesorado que presenta mayor preferencia por la investigación es el más joven mientras que el profesorado que muestra una mayor preferencia por la docencia es el de más edad. Esto se puede explicar por el hecho de que en la actualidad es muy importante la investigación en la carrera docente universitaria (acreditaciones para poder trabajar como docente y promocionar, tramos de investigación, reducciones docentes para poderse dedicar más a la investigación...) cosa que no sucedía con la misma intensidad en años anteriores (Tesouro y Puiggalí, 2015).

En la misma línea, fomentar la investigación científica en estudiantes por parte de los docentes puede incrementar la realización de trabajos de campo en los cuales se beneficien las distintas poblaciones en estudio. En consecuencia, se propone que los docentes desarrollen líneas de investigación de acuerdo con su especialidad y nivel de experiencia, en las que los estudiantes puedan comenzar su camino en la investigación, teniendo en cuenta que la influencia del docente es esencial para erradicar la apatía que afecta a los estudiantes de pregrado y para ampliar sus horizontes en la investigación (Rios, De Benedictis y D' Amico, 2019).

El reporte y liderazgo de mujeres en publicaciones científicas peruanas es aún minoritario y con un estancamiento en el tiempo, por lo que deben crearse redes de colaboración y capacitación que sean más inclusivas con las mujeres, para apoyar y dar sostenibilidad a este crecimiento (Centeno, Morales, Lopez y Mejia, 2020). De ahí la necesidad de establecer las guías de Equidad de Género y Sexo en la Investigación (SAGER) que están diseñadas principalmente para ayudar a las/los autoras/es en la elaboración de sus manuscritos, pero también son útiles para las/los editoras/es, como guardianes de la ciencia, para incorporar la evaluación de la existencia de hombres y mujeres y la perspectiva de

Para citar este artículo utilice la siguiente referencia: Flores Paredes, A.; Martín Pino Vanegas, Y.; Coila Pancca, D.; Condori Huanca, S.N.; Macedo Atamari, J.T. ; Ticona Quizá, A.M.; Zeballos Zapana, L. (2020). Producción científica y características de docentes universitarios de Educación Física del Perú. Sportis Sci J, 6 (3), 447-467.

DOI: https://doi.org/10.17979/sportis.2020.6.3.6600

http://revistas.udc.es/ 
género en todos los manuscritos como parte integral del proceso editorial (Heidari, Babor, De castro, Tort y Curno, 2019).

Tabla 3. Producción científica de las universidades que ofertan el programa de estudios de Educación Física del Perú período 2006-2020

\begin{tabular}{|c|c|c|c|c|c|c|c|c|c|c|}
\hline \multirow{2}{*}{ Revistas Indizadas } & \multicolumn{2}{|c|}{ UNMSM } & \multicolumn{2}{|c|}{ UNEGYV } & \multicolumn{2}{|c|}{ UNA } & \multicolumn{2}{|c|}{ UNSCH } & \multicolumn{2}{|c|}{ TOTAL } \\
\hline & $\mathrm{f}$ & $\%$ & $\mathrm{f}$ & $\%$ & $\mathrm{f}$ & $\%$ & $f$ & $\%$ & $f$ & $\%$ \\
\hline Scopus & 2 & 25.00 & 16 & 55.17 & 7 & 25.00 & 0 & 0.00 & 25 & 37.31 \\
\hline Web of Science & 6 & 75.00 & 4 & 13.79 & 12 & 42.86 & 1 & 50.00 & 23 & 34.33 \\
\hline Pub Med & 0 & 0.00 & 9 & 31.03 & 0 & 0.00 & 0 & 0.00 & 9 & 13.43 \\
\hline Scielo & 0 & 0.00 & 0 & 0.00 & 6 & 21.43 & 1 & 50.00 & 7 & 10.45 \\
\hline Latindex & 0 & 0.00 & 0 & 0.00 & 3 & 10.71 & 0 & 0.00 & 3 & 4.48 \\
\hline Total & 8 & 100.00 & 29 & 100.00 & 28 & 100.00 & 2 & 100.00 & 67 & 100.00 \\
\hline
\end{tabular}

La Universidad Nacional de Educación Enrique Guzmán y Valle (UNEGYV) presenta el mayor porcentaje de artículos científicos en Scopus (16) 55.17\%, Pub Med (9) 31.03\%, Web of Sience (4) 13.79\%; seguido de la Universidad Nacional del Altiplano (UNA) en Scopus (7) 25\%, Web of Science (12) 42.86\%, Scielo (6) $21.43 \%$, y en Latindex (3) $10.71 \%$; La Universidad Nacional Mayor de San Marcos en Scopus (2) 25\%, Web of Science (6) $75 \%$ y la Universidad Nacional San Cristóbal de Huamanga (UNSCH) ha publicado en Web of Science y Scielo (1) artículo en ambos casos representa el 50\%. Los docentes investigadores peruanos reconocidos por el RENACYT pertenecen a las Universidades de (UNEGYV), (UNA) y la (UNMSM), y el docente con mayor H-index pertenece a la (UNEGYV) con un (H-index: 6).

De la misma manera Candia, Ortiz, De león, Carrasco y Gutiérrez (2019) señalan que el uso de las revisiones sistematizadas para analizar la producción científica de las instituciones educativas superiores puede ser una herramienta muy útil para la toma de decisiones institucionales en materia de investigación.

Respecto a lo anterior, la tasa de publicación de docentes que evaluaron tesis en una Facultad de Ciencias de la Salud en el Perú y la tasa de publicación de los asesores de tesis de pregrado en Psicología de la Universidad, en ambos casos es baja y preocupante; lo cual evidencia grandes limitaciones respecto a las competencias investigativas en los docentes

Para citar este artículo utilice la siguiente referencia: Flores Paredes, A.; Martín Pino Vanegas, Y.; Coila Pancca, D.; Condori Huanca, S.N.; Macedo Atamari, J.T. ; Ticona Quizá, A.M.; Zeballos Zapana, L. (2020). Producción científica y características de docentes universitarios de Educación Física del Perú. Sportis Sci J, 6 (3), 447-467.

DOI: https://doi.org/10.17979/sportis.2020.6.3.6600

http://revistas.udc.es/ 
Artículo Original. Producción científica y características de docentes universitarios de Educación Física del Perú. Vol. 6, nº 3; p. 447-467, septiembre 2020. A Coruña. España ISSN 2386-8333

asesores, además, se revela que una gran parte de los involucrados ostenta aún el título profesional lo cual estaría develando una falta de capacitación y formación en investigación científica (Mamani, 2019; Mamani, Ventura y Caycho, 2019).

De manera análoga, se requiere construir una verdadera cultura científica en la comunidad universitaria, la desmitificación de la figura del científico como individuo poco común genial es decir, como un modelo casi inalcanzable, además de la promoción de la investigación colaborativa, la creación de estrategias individuales, grupales e institucionales para la publicación científica, la capacitación permanente y sistemática, un mayor estímulo por parte de los organismos que controlan la calidad de la educación (Barriga, Barbón, Buenaño y Barriga, 2018).

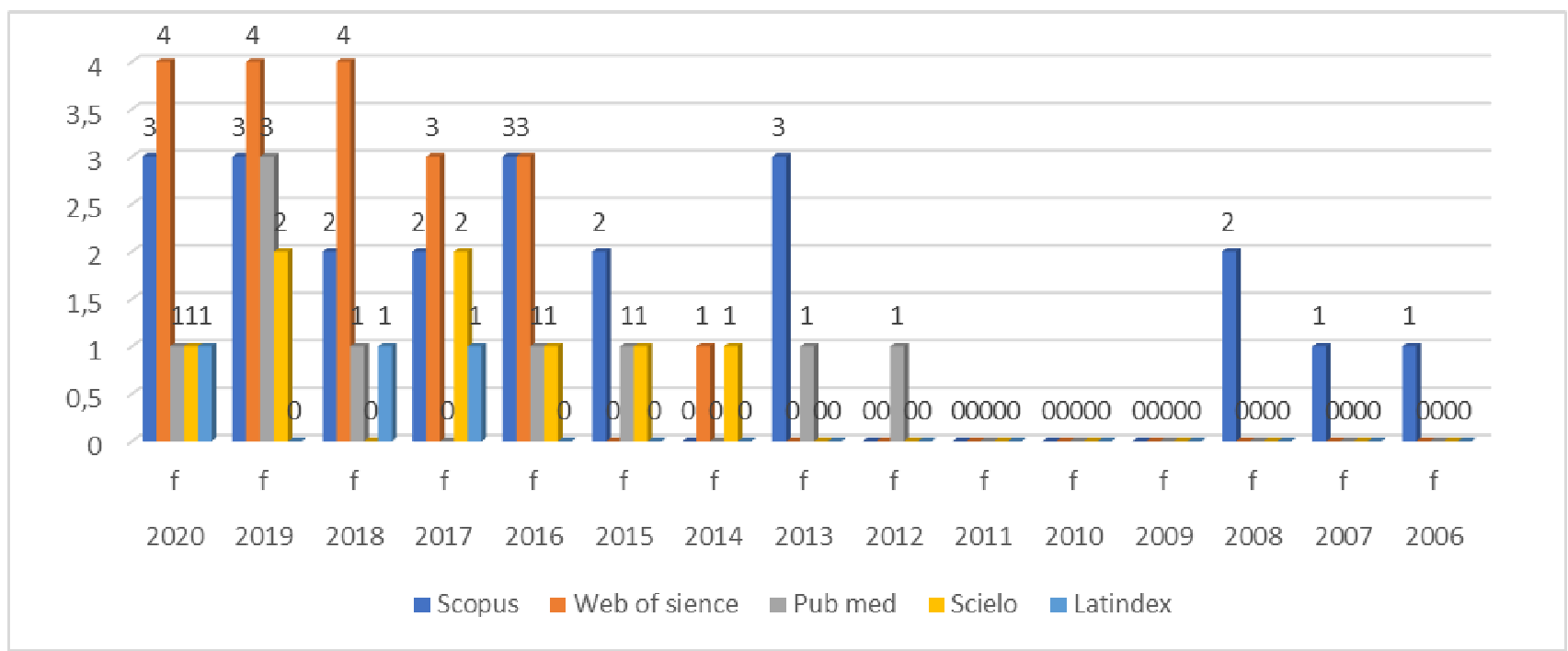

Figura 1. Producción científica por año de los docentes universitarios de Educación Física del Perú período 2006-2020

La producción científica se inició, el 2006 y 2007 en ambos años se publica (1) artículo en Scopus; 2008 (2) en Scopus; luego se tiene una ausencia de publicaciones en el período del 2009 al 2011; el 2012 (1) en Pub med; el 2013 (3) en Scopus y (1) en Pub Med; el 2014 (1) en Web of Science y Scielo, el 2015 (2) Scopus y (1) en Pub med y Scielo; 2016 (3) en Scopus y Web of Science, y (1) en Pub Med y Scielo, 2017 (3) en Web of Science, y 2 en Scopus y Scielo y (1) en Latindex; 2018 (4) en Web of Science, (2) en Scopus y (1) Pub Med

Para citar este artículo utilice la siguiente referencia: Flores Paredes, A.; Martín Pino Vanegas, Y.; Coila Pancca, D.; Condori Huanca, S.N.; Macedo Atamari, J.T. ; Ticona Quizá, A.M.; Zeballos Zapana, L. (2020). Producción científica y características de docentes universitarios de Educación Física del Perú. Sportis Sci J, 6 (3), 447-467.

DOI: https://doi.org/10.17979/sportis.2020.6.3.6600

http://revistas.udc.es/ 


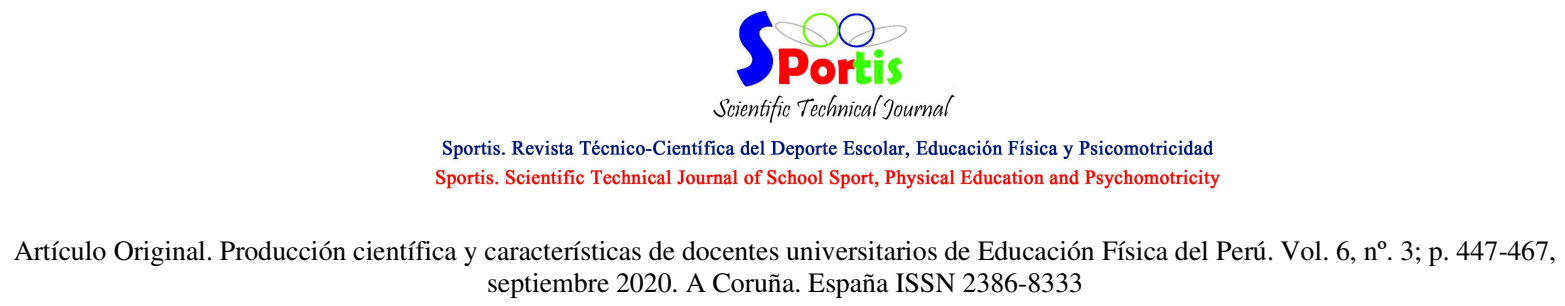

y Latindex; se incrementa de manera significativa el 2019 (4) en Web of sience, (3) en Scopus y Pub med y (2) en Scielo y el 2020 (4) en Web of Science, (3) en Scopus y (1) en Pub Med, Scielo y Latindex.

De otro lado (Reverter, Hernández, Jové y Legaz, 2016) señalan que las revistas donde más publican los profesores españoles son Medicine and Science in Sport and Exercise y Archivos de Medicina del Deporte en el área de Educación Física y la Revista Internacional de Medicina y Ciencias de la Actividad Física y del Deporte para el área de Didáctica de la Expresión Corporal. Los resultados muestran que los valores medios del Índice h son más elevados en Scopus.

Barbón, Barriga, Cazorla y Cepeda, (2018) constatan que el personal académico con un mayor número de publicaciones, tiene alrededor de 15 y 30 horas semanales asignadas para proyectos de investigación y producción científica. Asimismo, son necesarios mayores compromisos para fortalecer de mejor manera las prácticas de investigación y con ello la mejora en la enseñanza, para luego lograr las apropiaciones del fenómeno en mejor sentido (Casimiro, Casimiro y Casimiro, 2017).

De manera semejante (Gonzales, et al., 2018) concluyen que la producción científica de la Facultad de Medicina de la Universidad Nacional de Trujillo en MEDLINE/Pubmed y SCOPUS es baja. Es necesaria la implementación de estrategias que fomenten la producción científica involucrando a estudiantes, docentes, autoridades y egresados, así como la instauración de redes de colaboración que complementen las estrategias implementadas por CONCYTEC.

Igualmente Valles (2019) señala que para incrementar la producción científica se requiere de un nuevo modelo de gestión, basado en tres pilares: institucionalidad, para garantizar la adopción del modelo en la universidad; gestión de la investigación propiamente dicha, que busca fortalecer las competencias para la publicación de artículos científicos; y gestión administrativa, para asegurar las condiciones logísticas y operativas en la ejecución de los proyectos de investigación.

Para citar este artículo utilice la siguiente referencia: Flores Paredes, A.; Martín Pino Vanegas, Y.; Coila Pancca, D.; Condori Huanca, S.N.; Macedo Atamari, J.T. ; Ticona Quizá, A.M.; Zeballos Zapana, L. (2020). Producción científica y características de docentes universitarios de Educación Física del Perú. Sportis Sci J, 6 (3), 447-467.

DOI: https://doi.org/10.17979/sportis.2020.6.3.6600

http://revistas.udc.es/ 


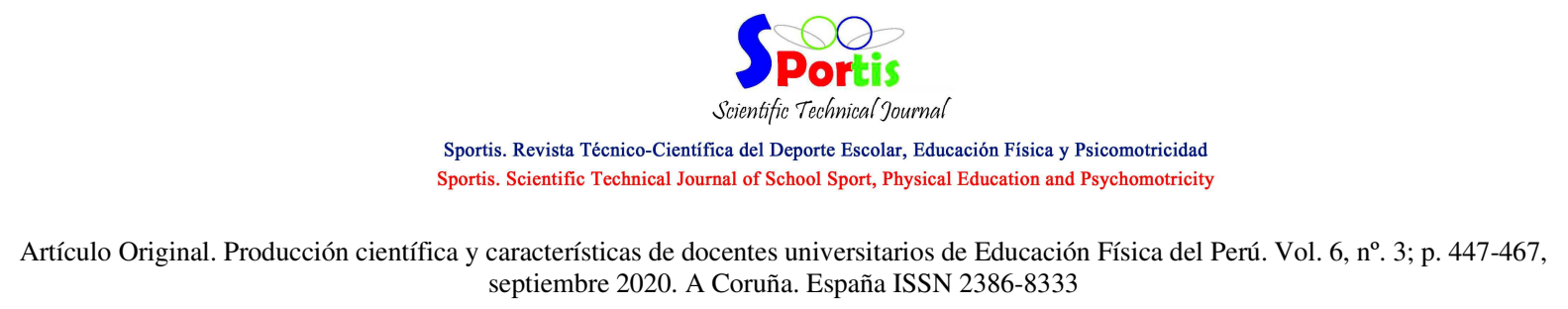

\section{Discusión}

La producción científica es un indicador del conocimiento generado por las instituciones y la divulgación la vía formal más mediata y activa de comunicación con la comunidad científica (Day, 2005) lo esencial sería encontrar a licenciados, magísteres y doctores con experiencia en investigación. Los resultados de nuestro estudio no reflejan que los docentes universitarios de Educación Física estén realizando investigación científica como parte de su labor docente en donde el mayor porcentaje de investigaciones lo realizaron (5) doctores con 25 publicaciones en Scopus, 10 en Web of sience, 9 en Pub med, 2 en Scielo y 2 en Latindex, en comparación a los magísteres, 1 en Web of Science y en Latindex. Y el $1.82 \%$ (3) docentes cuentan con la certificación de docente investigador reconocidos por el (RENACYT) del Perú.

Concordamos con (Mejia, Valladares y Valladares, 2018) en donde señala que: muy pocos magísteres (40\% y 15\%) y doctores (33\% y 11\%) habían publicado en Google Académico y Scopus, respectivamente. Aquellos que tenían una maestría más doctorado tuvieron mayores frecuencias de publicación de artículos originales en Google Académico (RPc: 1,52; IC 95\%: 1,05-2,21; valor $\mathrm{p}=0,028$ ), de publicar en los últimos 5 años cualquier investigación (RPc: 1,58; IC 95\%: 1,01-2,46; valor $\mathrm{p}=0,046)$ y publicar artículos originales (RPc: 1,77; IC 95\%: 1,11-2,84; valor $\mathrm{p}=0,017$ ). Los doctores tuvieron mayores frecuencias de publicación de artículos originales en los últimos 5 años (RPc: 1,59; IC 95\%: 1,03-2,47; valor $\mathrm{p}=0,037)$.

Por otra parte, (Barriga, et al., 2018) refieren que el impacto de un Programa Experiencial de Preparación para la Investigación, en el cual se privilegie el intercambio de experiencias prácticas de investigación y de temáticas solicitadas por los participantes, aumentó la producción de ponencias, de artículos científicos de revisión, de artículos originales y la publicación de artículos en revistas indexadas de forma significativa.

En España las redes de colaboración son multicéntricas y multidisciplinarias, involucrando varios grupos o comunidades con objetivos similares, con lo que se maximiza el uso de recursos favoreciendo la competitividad y producción en investigación; sin embargo la creación de redes de formación científica de los docentes aún constituyen tareas pendientes,

Para citar este artículo utilice la siguiente referencia: Flores Paredes, A.; Martín Pino Vanegas, Y.; Coila Pancca, D.; Condori Huanca, S.N.; Macedo Atamari, J.T. ; Ticona Quizá, A.M.; Zeballos Zapana, L. (2020). Producción científica y características de docentes universitarios de Educación Física del Perú. Sportis Sci J, 6 (3), 447-467.

DOI: https://doi.org/10.17979/sportis.2020.6.3.6600

http://revistas.udc.es/ 


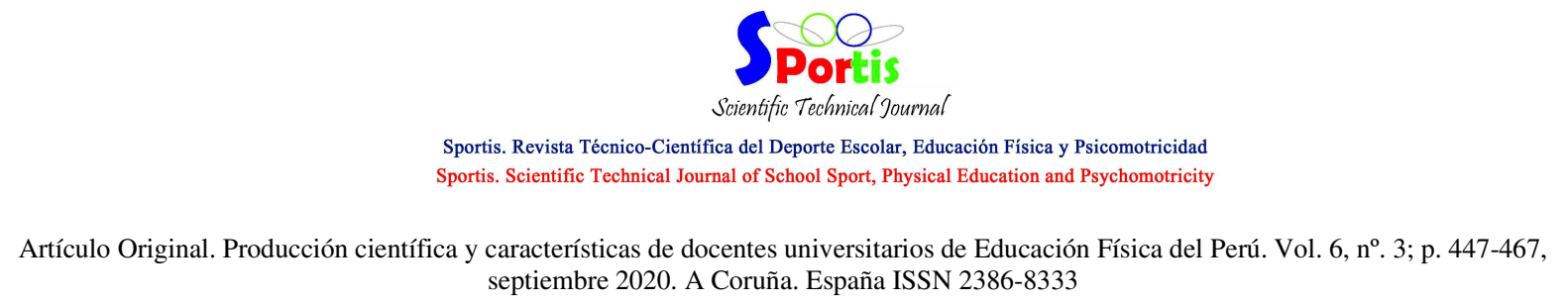

por una parte el desarrollo de estrategias para publicar sus trabajos científicos en las revistas académicas y por otra el reconocimiento del papel central que desempeñan las dificultades en la elaboración de artículos científicos y su vínculo con el origen de los mismos para sopesar las potencialidades (Barbón, et al., 2019; Fernández, et al., 2003).

\section{Conclusiones}

Se concluye que son muy bajas las frecuencias de publicaciones de los docentes universitarios del Perú de Educación Física con título profesional, maestrías y doctorados. Se necesita implementar políticas destinadas a cambiar los indicadores de producción científica en este grupo de docentes posgraduados. Se deben, realizar estudios similares en poblaciones de docentes con títulos de maestría y doctorado donde se evalúen y examinen las publicaciones científicas derivadas directamente de las tesis de maestría y doctorales, para instituir comparaciones con otros países, analizando los factores implicados en las bajas tasas de publicación de esta población de docentes.

\section{Limitaciones}

Las limitaciones que se tuvieron es que los resultados solo consideraron a docentes que estuvieron registrados en la (SUNEDU) del Perú y se sabe que puede haber otros profesionales con títulos no homologados y no registrados que pudiesen tener una importante publicación científica. Otra limitación fue el no considerar la variable de la mención de la obtención de los grados académicos de maestría y doctorado a nivel nacional e internacional. A pesar de estas limitaciones los resultados son importantes, porque reflejan una realidad de la producción científica que presenta la docencia universitaria de Educación Física del Perú.

\section{Agradecimientos}

A los docentes universitarios de Educación Física de las diferentes universidades del Perú, por su apoyo incondicional en la presente investigación.

Para citar este artículo utilice la siguiente referencia: Flores Paredes, A.; Martín Pino Vanegas, Y.; Coila Pancca, D.; Condori Huanca, S.N.; Macedo Atamari, J.T. ; Ticona Quizá, A.M.; Zeballos Zapana, L. (2020). Producción científica y características de docentes universitarios de Educación Física del Perú. Sportis Sci J, 6 (3), 447-467.

DOI: https://doi.org/10.17979/sportis.2020.6.3.6600

http://revistas.udc.es/ 


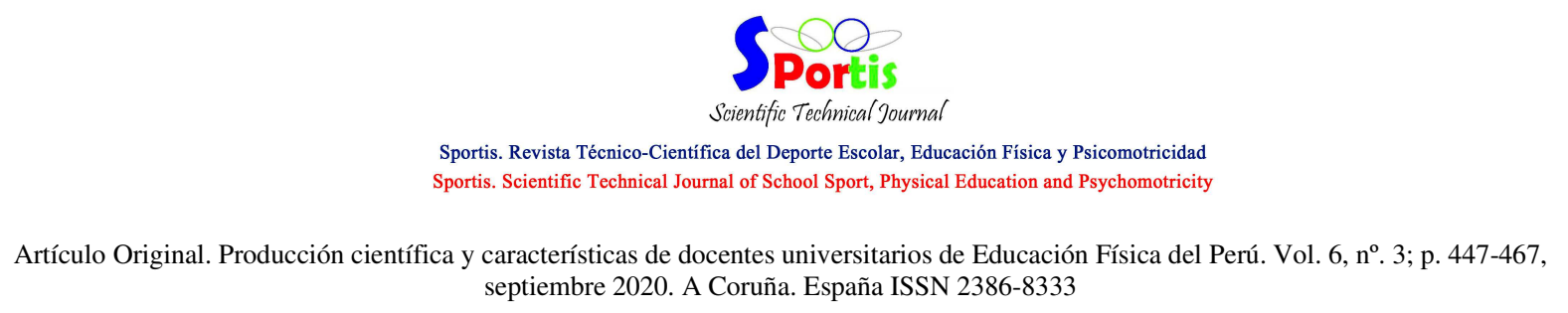

\section{Referencias bibliográficas}

Arechavala Vargas, R., y Sánchez Cervantes, C. F. (2017). Las universidades públicas mexicanas: los retos de las transformaciones institucionales hacia la investigación y la transferencia de conocimiento. Revista de La Educación Superior, 46(184), 21-37. DOI: https://doi.org/10.1016/j.resu.2017.09.001

Barbón Pérez, O. G., Calderón Tobar, Á. del R., Buenaño Pesántez, C. V., Pimienta Concepción, I., Camaño Carballo, L., y Poalasín Narváez, L. A. (2019). La elaboración de la sección "Discusión" de artículos científicos originales. ¿Un reto para los docentes universitarios? Educación Médica, 20(6), 380-386. DOI: https://doi.org/10.1016/j.edumed.2017.12.011

Barbón Pérez, O. G., Barriga, S. F., Cazorla, A. L., y Cepeda, L. G. (2018). Influencia de la antigüedad y del total de horas de investigación en la producción científica de docentes universitarios. Formación Universitaria, 11(4), 75-82. DOI: https://doi.org/10.4067/S0718-50062018000400075

Barbón Pérez, O. G., y Bascó Fuentes, E. L. (2016). Clasificación de la actividad científica estudiantil en la educación médica superior. Educación Médica, 17(2), 55-60. DOI: https://doi.org/10.1016/j.edumed.2016.02.001

Barra, A. M. (2019). La importancia de la productividad científica en la acreditación institucional de universidades chilenas. Formación Universitaria, 12(3), 101-110. DOI: https://doi.org/10.4067/S0718-50062019000300101

Barriga, S.F., Barbón, O.G., Buenaño, C.V., y Barriga, L. F. (2018). Impacto en la producción científica de un programa experiencial de preparación para la investigación dirigido a docentes universitarios. Formación Universitaria, 11(3), 41-48. DOI: https://doi.org/10.4067/S0718-50062018000300041

Candia Luján, R., Ortiz Rodríguez, B., De León Fierro, L. G., Carrasco Legleu, C. E., y Gutiérrez Chávez, P. N. (2019). Producción científica histórica de la Universidad Autónoma de Chihuahua: una revisión sistematizada. Producción Bibliotecológica, 33, 83-98.DOI: https://doi.org/10.22201/iibi.24488321xe.2019.79.57967

Para citar este artículo utilice la siguiente referencia: Flores Paredes, A.; Martín Pino Vanegas, Y.; Coila Pancca, D.; Condori Huanca, S.N.; Macedo Atamari, J.T. ; Ticona Quizá, A.M.; Zeballos Zapana, L. (2020). Producción científica y características de docentes universitarios de Educación Física del Perú. Sportis Sci J, 6 (3), 447-467.

DOI: https://doi.org/10.17979/sportis.2020.6.3.6600

http://revistas.udc.es/ 
Carranza Esteban, R. F., y Turpo Chaparro, J. E. (2019). Limitantes de la producción y publicación científica universitaria. Educación Médica, 20, 185-186. DOI: https://doi.org/10.1016/j.edumed.2017.12.002

Casimiro Urcos, W. H., Casimiro Urcos, C. N., y Casimiro Urcos, J. F. (2017). Apropiación de dinámicas de investigación en docentes universitarios. Un estudio fenomenológico*. Universidad del Zulia, 33(83), 336-372.

Centeno Leguía, D., Morales Concha, L., Lopez, C. E., y Mejia, C. R. (2020). Mujeres científicas: características y factores asociados a la primera autoría y corresponsalía en revistas peruanas indizadas a SciELO, 2010-2015. Educación Médica, 21(1), 17-23. DOI: https://doi.org/10.1016/j.edumed.2018.04.010

Chachaima Mar, J. E., Fernández Guzmán, D., y Atamari Anahui, N. (2019). Publicación científica de docentes de una escuela de medicina peruana: frecuencia y características asociadas. $\quad$ Educación $\quad$ Médica, 20(S2), 2-9. DOI: https://doi.org/10.1016/j.edumed.2017.10.024

Consejo Nacional de Ciencia y Tecnología (CONCYTEC). (2014). Principales indicadores bibliométricos de la actividad científica peruana 2006-2011. San Borja-Lima-Perú.

Day, R. A. (2005). Cómo escribir y publicar trabajos científicos. Publicación científica y técnica (3ra ed.). Washington: Organización Panamericana de la Salud.

Fernández Fernández, I., Bolívar, B., Grandes, G., Lloberas, J., Férnandez, C., y Martín Zurro, A. (2003). Redes temáticas de investigación cooperativa. Editorial SemFYC. Atención Primaria, 32(9), 505-508. DOI: https://doi.org/10.1016/S02126567(03)70778-1

Fernandez Vaz, A., Quintão de Almeida, F., y Bassani, J. J. (2017). De la investigación y de la práctica pedagógica. Revista Brasileira de Ciencias Do Esporte, 39(4), 329. DOI: https://doi.org/10.1016/j.rbce.2017.08.001

Gonzales Saldaña, J., Chavez Uceda, T., Lemus Arteaga, K., Silva Ocas, I., Galvez Olortegui, T., y Galvez-Olortegui, J. (2018). Producción científica de la Facultad de Medicina de una universidad peruana en SCOPUS y PUBMED. Educación Médica, 19(S2), 128134. DOI: https://doi.org/10.1016/j.edumed.2017.01.010

Para citar este artículo utilice la siguiente referencia: Flores Paredes, A.; Martín Pino Vanegas, Y.; Coila Pancca, D.; Condori Huanca, S.N.; Macedo Atamari, J.T. ; Ticona Quizá, A.M.; Zeballos Zapana, L. (2020). Producción científica y características de docentes universitarios de Educación Física del Perú. Sportis Sci J, 6 (3), 447-467.

DOI: https://doi.org/10.17979/sportis.2020.6.3.6600

http://revistas.udc.es/ 
González Aguilar, H., y Rubio Pachamango, A. (2019). La estructura de la crítica científica. Educación

Médica, 20(6), 392-393.

DOI: https://doi.org/10.1016/j.edumed.2018.05.009

Gutiérrez Rojas, I. R., Peralta Benítez, H., y Fuentes González, H. C. (2019). Integración de la investigación y la enseñanza en las universidades médicas. Educación Médica, 20(1), 49-54. DOI: https://doi.org/10.1016/j.edumed.2018.07.007

Heidari, S., Babor, T. F., De Castro, P., Tort, S., y Curno, M. (2019). Equidad según sexo y de género en la investigación: justificación de las guías SAGER y recomendaciones para uso. Gaceta Sanitaria, 33(2), 203-210. DOI: https://doi.org/10.1016/j.gaceta.2018.04.003

Hernández Sampieri, R., Fernández Collado, C. y Baptista Lucio, P. (2006). Metodología de la investigación. (M.H. Interamericana, Ed.) (Cuarta Edi). México.

Hortigüela Alcalá, D., Ausín Villaverde, V., Delgado Benito, V., y Abella García, V. (2017). Análisis de la importancia de los criterios de evaluación y el reconocimiento académico docente universitario como indicadores de la calidad educativa en España. Revista de la Educación Superior, 46(181), 75-87. DOI: https://doi.org/10.1016/j.resu.2016.10.002

King Domínguez, A., Llinàs Audet, X., y Améstica Rivas, L. (2020). Caracterización de la producción científica sobre clasificaciones de universidades. Un estudio bibliométrico desde 1988 a 2018. Formación Universitaria, 13(2), 53-62. DOI: https://doi.org/10.4067/S0718-50062020000200053

Linn, M.C., Palmer, E., Baranger, A., Gerard, E., \& Stone, E. (2015). Undergraduate research experiences: Impacts and opportunities. Science, 347(6222), 1-6. DOI: https://doi.org/10.1126/science.1261757

López Köstner, F., y Zárate, A. J. (2019). Implementación de un equipo de investigación en una institución de salud privada: Experiencia. Revista Médica Clínica Las Condes, 30(1), 66-69. DOI: https://doi.org/10.1016/j.rmclc.2019.01.001

Para citar este artículo utilice la siguiente referencia: Flores Paredes, A.; Martín Pino Vanegas, Y.; Coila Pancca, D.; Condori Huanca, S.N.; Macedo Atamari, J.T. ; Ticona Quizá, A.M.; Zeballos Zapana, L. (2020). Producción científica y características de docentes universitarios de Educación Física del Perú. Sportis Sci J, 6 (3), 447-467.

DOI: https://doi.org/10.17979/sportis.2020.6.3.6600

http://revistas.udc.es/ 


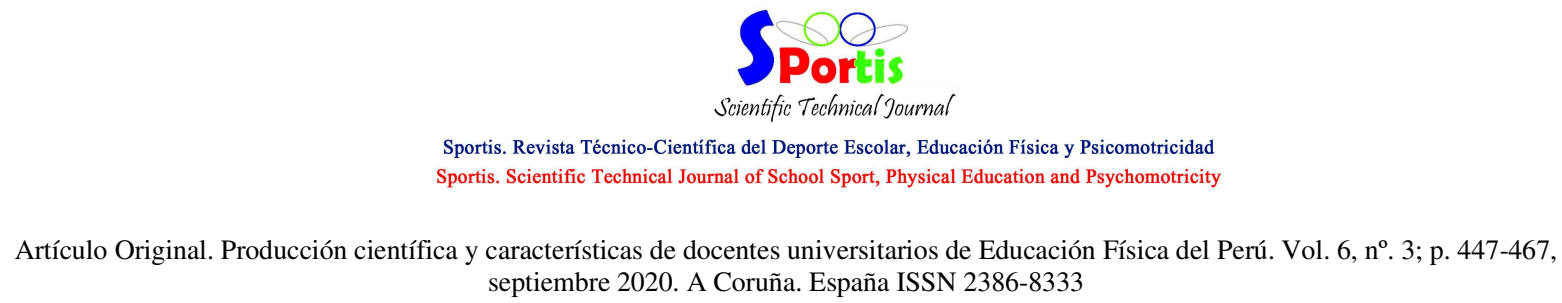

Luque Martínez, T. (2015). Actividad investigadora y contexto económico. El caso de las universidades públicas españolas, 38(1), 1-16. DOI: https://doi.org/10.3989/redc.2015.1.1135

Mamani Benito, O. J. (2019). Publicación científica y características de asesores de tesis de una escuela de psicología peruana. Apuntes Universitarios, 9(2), 27-36. DOI: https://doi.org/10.17162/au.v9i2.356

Mamani Benito, O., Ventura León, J., y Caycho Rodríguez, T. (2019). Publicación científica de docentes que conforman el jurado dictaminador de tesis en una Facultad de Ciencias de la Salud peruana. Revista Cubana de Información En Ciencias de La Salud, 30(3), 1-9. DOI: https://doi.org/10.17162/au.v9i2.152

Mejia, C. R., Valladares Garrido, M. J., y Valladares Garrido, D. (2018). Baja publicación en revistas científicas de médicos peruanos con doctorado o maestría: frecuencia y características asociadas. Educación Médica, 19(S2), 135-141. DOI: https://doi.org/10.1016/j.edumed.2017.01.009

Normas Legales, El Peruano. Ley Universitaria N³0220. (2014). Perú. Retrieved from. DOI: http://www.leyes.congreso.gob.pe/Documentos/Leyes/30143.pdf

Pascual, Á., y Martínez Martínez, L. (2010). Las publicaciones científicas y su influencia en la docencia de la especialidad. Enfermedades Infecciosas y Microbiología Clínica, 28(Supl 3), 25-30. DOI: https://doi.org/10.1016/S0213-005X(10)70016-1

Reverter Masia, J., Hernández González, V., Jové Deltell, C., y Legaz Arrese, A. (2016). Producción en Web of Science y Scopus de profesores funcionarios con sexenio de las ciencias del deporte en España. Revista Interamericana de Bibliotecología, 39(2), 149162. DOI: https://doi.org/10.17533/udea.rib.v39n2a06

Rios González, C. M., De Benedictis Serrano, G., y D’ Amico López, R. (2019). El rol docente en la promoción de la investigación científica en pregrado. Educación Médica, 20, 187-188. DOI: https://doi.org/10.1016/j.edumed.2017.07.021

Rodríguez Menéndez, M., González Cantalapiedra, Z., y González Polo, M. (2016). Problemas frecuentes en la redacción de artículos científicos. EduSol, 16(57), 137147. Retrieved from https://dialnet.unirioja.es/servlet/articulo.

Para citar este artículo utilice la siguiente referencia: Flores Paredes, A.; Martín Pino Vanegas, Y.; Coila Pancca, D.; Condori Huanca, S.N.; Macedo Atamari, J.T. ; Ticona Quizá, A.M.; Zeballos Zapana, L. (2020). Producción científica y características de docentes universitarios de Educación Física del Perú. Sportis Sci J, 6 (3), 447-467.

DOI: https://doi.org/10.17979/sportis.2020.6.3.6600

http://revistas.udc.es/ 


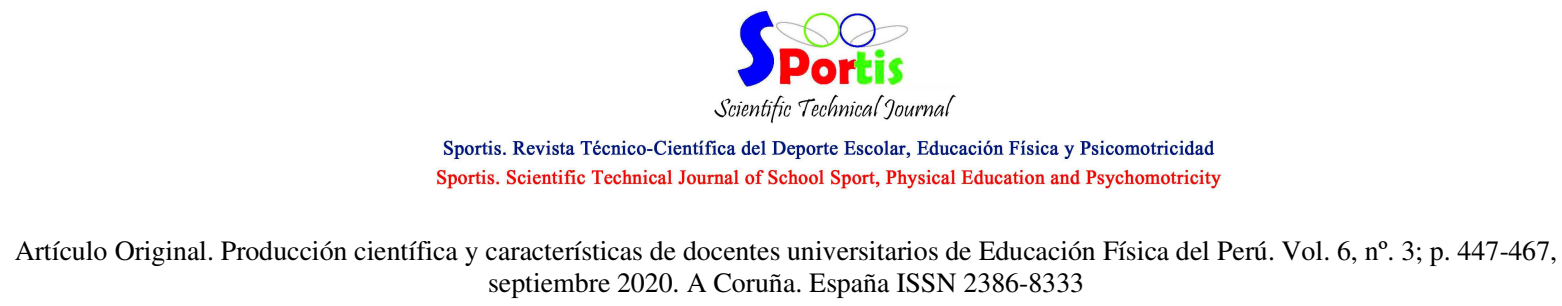

Rodríguez Miramontes, J., González Brambila, C. N., y Maqueda Rodríguez, G. (2017). El sistema nacional de investigadores en México: 20 años de producción científica en las instituciones de educación superior (1991-2011). Investigación Bibliotecológica, 2017(Special Issue), 187-219. DOI: https://doi.org/10.22201/iibi.24488321xe.2017.nesp1.57890

Scimago, S. (2020). Scimago Journal y Country Rank. Retrieved from https://www.scimagojr.com/

Sime Poma, L. (2017). Grupos de investigación en educación: hacia una tipología multirreferencial desde casos representativos. Revista de La Educación Superior, 46(184), 97-116. DOI: https://doi.org/10.1016/j.resu.2017.12.002

Superintendencia Nacional de Educación Superior Universitaria (SUNEDU). (2016). Informe bienal sobre la realidad universitaria peruana (Vol. 1). Retrieved from https://www.sunedu.gob.pe/informe-bienal-sobre-realidad-universitaria/

Tesouro, M., y Puiggalí, J. (2015). La relación entre la docencia y la investigación según la opinión del profesorado universitario. Procedia - Social and Behavioral Sciences, 196(July 2014), 212-218. DOI: https://doi.org/10.1016/j.sbspro.2015.07.031

Valles Coral, M. A. (2019). Modelo de gestión de la investigación para incrementar la producción científica de los docentes universitarios del Perú. Revi.Investig.Desarro.Innov., $\quad$ 10(1), 67-78. DOI: https://doi.org/10.19053/20278306.v10.n1.2019.10012

Vasen, F., y Vilchis, I. L. (2017). Sistemas nacionales de clasificación de revistas científicas en América Latina: tendencias recientes e implicaciones para la evaluación académica en ciencias sociales. Revista Mexicana de Ciencias Políticas y Sociales, 62(231), 199228. DOI: https://doi.org/10.1016/S0185-1918(17)30043-0

Para citar este artículo utilice la siguiente referencia: Flores Paredes, A.; Martín Pino Vanegas, Y.; Coila Pancca, D.; Condori Huanca, S.N.; Macedo Atamari, J.T. ; Ticona Quizá, A.M.; Zeballos Zapana, L. (2020). Producción científica y características de docentes universitarios de Educación Física del Perú. Sportis Sci J, 6 (3), 447-467.

DOI: https://doi.org/10.17979/sportis.2020.6.3.6600

http://revistas.udc.es/ 